\title{
Síndrome de lisis de glóbulos blancos después de un trasplante autólogo de células troncales hematopoyéticas en el tratamiento de la amiloidosis AL renal. Caso clínico
}

\author{
Antonio Gatica $\mathbf{M}^{1}$, Pablo Bertin $\mathrm{C}^{2}$, Rodrigo Tagle $\mathbf{V}^{1}$. \\ White blood cell lysis syndrome \\ after autologous peripheral blood stem \\ cell transplantation in the treatment \\ of renal AL amyloidosis. Case report
}

\begin{abstract}
The treatment of AL amyloidosis was not successful until the advent of myeloablative chemotherapy consisting of high-dose intravenous melphalan followed by autologous peripheral blood stem cell transplantation. This new treatment has achieved better survival rates and, remarkably, it has obtained complete remission. Among patients with renal involvement, achievement of a complete hematological response was associated with a $50 \%$ reduction in proteinuria and stable creatinine clearance in more than 2/3 of patients. Despite of these excellent results, this new therapy is associated with significant toxicity, including the development of acute renal failure due to white blood cell lysis syndrome. We report a 59 year-old female with a nephrotic syndrome due to primary amyloidosis successfully treated autologous stem cell transplantation who developed acute renal failure caused by white blood cell lysis syndrome. The patient required treatment with granulocytic colony stimulating factor and intermittent hemofiltration and was discharged 23 days after melphalan administration with a satisfactory renal function and white blood cell count. After one year of follow up, she maintains a good glomerular filtration rate, a proteinuria of less than, $1 \mathrm{~g} /$ day and normal hematological values (Rev Méd Chile 2006; 134: 763-6).
\end{abstract}

(Key words: Amyloidosis, familial; Kidney failure, acute; Stem cell transplantation, hematopoietic)

Recibido el 28 de febrero, 2005. Aceptado el 1 de diciembre, 2005.

${ }^{1}$ Departamentos de Nefrología y ${ }^{2}$ Hematología, Facultad de Medicina, Pontificia Universidad Católica de Chile. Santiago, Chile.

T a amiloidosis $\mathrm{AL}$, la forma más frecuente de _amiloidosis sistémica, es una discrasia clonal

Correspondencia a: Dr. Rodrigo Tagle Vargas. Departamento de Nefrología, Pontificia Universidad Católica de Chile. Lira $854^{\circ}$ Piso, Santiago, Chile. Fax: 02-6397377. E mail: rtagle@med.puc.cl de células plasmáticas, caracterizada por depósito tisular de fibrillas compuestas de cadenas livianas de inmunoglobulinas monoclonales. La acumulación de estos depósitos determina deterioro orgánico progresivo, $\mathrm{y}$, finalmente, conduce a la muerte. La sobrevida promedio de pacientes con 
amiloidosis AL sin tratamiento es un año, y menos de seis meses si existe compromiso miocárdico ${ }^{1}$. El tratamiento con melfalán oral y prednisona es escasamente efectivo, prolongando discretamente la sobrevida, sin eliminar la discrasia clonal subyacente $^{2,3}$. Diversos esquemas de quimioterapia alternativos tampoco han tenido impacto en la sobrevida ${ }^{4}$.

Recientemente se ha reportado mejoría significativa en la sobrevida a largo plazo y regresión del compromiso orgánico en pacientes con amiloidosis $\mathrm{AL}$, usando dosis mieloablativas de melfalán y trasplante autólogo de células troncales hematopoyéticas $^{5}$. Sin embargo, existe una significativa toxicidad relacionada con esta terapia, con mortalidad precoz de $13 \%$. Además, alrededor de $20 \%$ de los pacientes desarrolla insuficiencia renal aguda (IRA) y 5\% requiere diálisis ${ }^{5-7}$. Entre las variadas causas de IRA relacionadas a la terapia está el síndrome de lisis de glóbulos blancos (SLGB) ${ }^{6}$. Éste corresponde a un cuadro similar al síndrome de lisis tumoral, en que el número de glóbulos blancos habitualmente elevado al momento de la administración de melfalán, disminuye drásticamente, y coincidente con ello aparecen hiperfosfatemia, hiperuricemia, hipocalcemia e IRA.

Presentamos una paciente con amiloidosis AL renal, tratada exitosamente con dosis altas de melfalán endovenoso y trasplante autólogo de células troncales hematopoyéticas, quien presentó IRA secundaria a SLGB post-melfalán.

\section{CASO CLÍNICO}

Mujer de 59 años, sin antecedentes mórbidos. Veintiocho meses pretrasplante debutó con edema y orina espumosa, objetivándose síndrome nefrótico con proteinuria hasta $9 \mathrm{~g} /$ día e hipoalbuminemia 1,9 $\mathrm{g} / \mathrm{dL}$ El clearance de creatinina y la presión arterial eran normales. El estudio etiológico incluyó exámenes de laboratorio inmunológico (anticuerpos antinucleares, anticuerpos antiADN, anticuerpos anticitoplasma de neutrófilos, complementemia), viral (antígeno de superficie de virus hepatitis B, anticuerpos antivirus hepatitis $\mathrm{C}$, virus de inmunodeficiencia humana), y electroforesis de proteína en sangre, los que resultaron normales. La búsqueda de una neoplasia sólida resultó negativa, incluyendo mamografía, radiografía de tórax, ecotomografía abdominal y pelviana, endoscopia digestiva alta y colonoscopia. Se realizó biopsia renal 24 meses pretrasplante, que reveló amiloidosis. La tinción con Rojo de Congo, y Rojo de Congo con permanganato de potasio fueron ambas muy tenuemente positivas en glomérulos y vasos sanguíneos. En la microscopia electrónica se observó desaparición pedicelar parcelar y depósitos densos de material amiloideo en la zona mesangial y en algunas asas capilares libres, de aspecto fibrilar, con fibrillas de un espesor promedio de 100 Angström. Un estudio posterior con inmunofijación sérica y urinaria resultó positivo para IgA-lambda monoclonal. La cuantificación de inmunoglobulinas séricas reveló IgA $1.000 \mathrm{mg} / \mathrm{dL}$, IgG $852 \mathrm{mg} / \mathrm{dL}$ e IgM $93 \mathrm{mg} / \mathrm{dL}$ El mielograma y la citometría de flujo de médula ósea descartaron un mieloma múltiple. Recibió tratamiento con melfalán oral y prednisona durante 6 meses, persistiendo la proteinuria nefrótica y la inmunofijación sérica positiva. Posteriormente se mantuvo sólo con terapia inespecífica que incluyó enalapril, espironolactona y atorvastatina. Tres meses pretrasplante se mantenía la presencia de proteína monoclonal y de síndrome nefrótico, con filtración glomerular normal. Un ecocardiograma transtorácico y una ventriculografía isotópica fueron normales.

En enero de 2004 se efectuó acondicionamiento medular con factor estimulante de colonias granulocíticas por cinco días, y cosecha mediante leucoaféresis de sangre periférica de 2,6 x $10^{6}$ células troncales hematopoyéticas. Recibió melfalán endovenoso $200 \mathrm{mg} / \mathrm{m}^{2}$ de superficie corporal (día 0) y al día siguiente se realizó infusión única de las células troncales. A partir del día 2 desarrolló IRA oligúnica, con fracción excretada de sodio $2 \%$, índice uricosunia/creatininuria $<1,0$ a $\mathrm{pH}$ urinario 7,0 , ecografíadoppler renal normal, creatinquinasa total sérica 285 $\mathrm{U} / \mathrm{L}$, ausencia de trombocitopenia o esquistocitosis y actividad de ADAMTS13 de 20\%. El deterioro de función renal se acompañó de evidencias de lisis celular (láctico-deshidrogenasa hasta $6.710 \mathrm{U} / \mathrm{L}$, fosfatemia hasta $9,2 \mathrm{mg} / \mathrm{dL}$, uricemia hasta $13,2 \mathrm{mg} / \mathrm{dL}$, transaminasa glutámico oxaloacética $351 \mathrm{U} / \mathrm{L}$ ) y rápido ascenso (hasta 28.000 células $/ \mathrm{mm}^{3}$ ) y posterior descenso del recuento de glóbulos blancos en sangre periférica, llegando hasta una completa aplasia que se prolongó por 12 días. En la Tabla 1 se detalla la evolución de algunos parámetros de laboratorio representativos. La paciente requirió del uso de factor estimulante de colonias granulocíticas 
entre los días 2 y 16 y de terapia de sustitución renal con hemodiafiltración veno-venosa intermitente diaria entre los días 5 al 14. Desde el día 13 recuperó diuresis y fue dada de alta el día 23 post-melfalán, con creatininemia $1,2 \mathrm{mg} / \mathrm{dL}$ y recuento de glóbulos blancos $3.000 / \mathrm{mm}^{3}$.

El control clínico al año de seguimiento reveló excelente estado general, filtración glomerular y recuentos hematológicos normales, proteinuria $<1$ g/día, e inmunofijación sérica negativa.

\section{DisCUSIÓN}

El uso de melfalán endovenoso en dosis altas y trasplante autólogo de células troncales hematopoyéticas en pacientes seleccionados con amiloidosis $\mathrm{AL}$ ha demostrado, a largo plazo, ser efectivo en prolongar la sobrevida, revertir la disfunción orgánica, e inducir respuesta hematológica completa ${ }^{5}$. Los criterios usados para excluir pacientes de esta terapia en la serie de Skinner y cols $^{5}$, fueron edad mayor de 80 años, insuficiencia cardíaca descompensada, hipotensión sistólica, hipoxemia, derrame pleural persistente o deterioro grave evaluado por una escala de desempeño global. Utilizando estos criterios, la sobrevida promedio fue de 4,6 años, y de 6,4 años en ausencia de compromiso miocárdico.

Nuestra paciente era portadora de amiloidosis $\mathrm{AL}$, diagnosticada por la concomitancia de IgA lambda monoclonal en inmunofijación sérica y urinaria, y depósitos de fibrillas de amiloide en la biopsia renal, sin evidencias de mieloma múltiple. A excepción del síndrome nefrótico, no presentaba compromiso de otros órganos, incluyendo ausencia de signos clínicos y ecográficos de compromiso miocárdico. La presencia de proteína monoclonal y síndrome nefrótico no se modificó con el uso de melfalán oral y prednisona, ni con terapia inespecífica que incluyó un inhibidor de enzima convertidora de angiotensina II, un antagonista del receptor de aldosterona y una estatina. La magnitud del síndrome nefrótico y el deterioro significativo en la calidad de vida de la paciente, en ausencia de criterios de exclusión, determinaron el uso de melfalán en dosis altas y trasplante autólogo de células troncales hematopoyéticas.

Se ha comunicado una mortalidad precoz relacionada a esta terapia de hasta $15 \%$ a los 100 días, particularmente en pacientes con compromiso miocárdico por amiloide ${ }^{5}$. Las principales causas de muerte incluyen complicaciones cardíacas y sépticas. Además, la morbilidad durante el período postrasplante es frecuente, incluyendo infecciones oportunistas, hemorragia digestiva, rotura esplénica e IRA. Esta última ocurre en alrededor de $20 \%$ de los pacientes, habitualmente durante los primeros 10 días postrasplante. La recuperación de la función renal ocurre en aproximadamente el $50 \%$ de los casos y el $25 \%$ de los pacientes con IRA requiere de diálisis. La existencia de IRA aumenta la mortalidad precoz postrasplante, pero no modifica la sobrevida a largo plazo ${ }^{5,6}$. En la mayoría de los pacientes la causa de la IRA parece ser multifactorial, existiendo evidencias de necrosis tubular aguda en $35 \%$ de los casos y de SLGB en $14 \% 6$. El potencial nefrotóxico directo del melfalán en altas dosis ha sido sugerido en escasos reportes ${ }^{8}$, sin embargo no es posible excluir completamente factores confundentes tales como la depleción de volumen intravascular, debida a la mayor gravedad

Tabla 1. Evolución de parámetros séricos respecto al momento de la administración de melfalán (día 0)

\begin{tabular}{|c|c|c|c|c|c|c|c|c|}
\hline Parámetros séricos & Día 0 & Día 2 & Día 3 & Día 5 & Día 7 & Día 9 & Día 14 & Día 21 \\
\hline Creatinina (mg/dL) & 0,6 & 2,0 & 3,5 & 5,8 & 3,9 & 4,2 & 4,5 & 1,2 \\
\hline Nitrógeno ureico (mg/dL) & & 64 & 93 & 122 & 63 & 56 & 65 & 56 \\
\hline Láctico deshidrogenasa (U/L) & 360 & 6.710 & 5.450 & 756 & 490 & 453 & & \\
\hline Potasio (mEq/L) & 3,5 & 5,3 & 4,6 & 4,8 & 3,5 & 4,1 & 3,5 & 3,4 \\
\hline Calcio (mg/dL) & 8,6 & 7,2 & 7,2 & 7,3 & 8,0 & 8,0 & & \\
\hline Fósforo (mg/dL) & 4,2 & 6,7 & 7,3 & 9,2 & 4,6 & 4,8 & & \\
\hline Ácido úrico (mg/dL) & 4,1 & 11,6 & 13,2 & 12,2 & 4,3 & 3,7 & & \\
\hline Recuento blancos (cél/mm³) & 28.000 & 14.100 & 22.100 & 200 & 0 & 100 & 500 & 3.300 \\
\hline
\end{tabular}


de la mucositis de los pacientes que reciben mayores dosis de melfalán ${ }^{6}$.

El SLGB resulta del efecto lítico del melfalán en dosis altas, en el contexto de una marcada leucocitosis inducida por el uso de factor estimulante de colonias como acondicionamiento antes de la cosecha de las células troncales ${ }^{9}$. No juega un rol el efecto sobre el clon de células plasmáticas amiloidogénico, ya que éste se encuentra habitualmente en bajas cantidades y no es un tipo celular altamente proliferativo. Este síndrome se asemeja al síndrome de lisis tumoral, manifestándose por hiperfosfatemia, hiperuricemia e hipocalcemia. La incidencia de IRA es más frecuente si existe algún grado de disfunción renal previa y generalmente es reversible ${ }^{6}$. La profilaxis con alopurinol no es efectiva y se presume que tenga un rol la precipitación de calcio-fósforo en el parénquima y/o vasculatura renal.

La paciente que describimos tenía proteinuria en rango nefrótico previo al tratamiento, con función renal normal. Desarrolló en las primeras $48 \mathrm{~h}$ deterioro de función renal asociado a oliguria, requiriendo iniciar hemodiafiltración el día 5 postmelfalán. Requirió terapia de sustitución renal durante 8 días, recuperando finalmente la diuresis $\mathrm{y}$

\section{REFERENCIAS}

1. Falk RH, Comenzo RL, SkinNer M. The systemic amyloidoses. N Engl J Med 1997; 337: 898-909.

2. SkinNer M, ANderson J, Simms R et al. Treatment of 100 patients with primary amyloidosis: a randomized trial of melphalan, prednisone and colchicine versus colchicine only. Am J Med 1996; 100: 290-8.

3. Kyle RA, Gertz MA, GreipP PR, Witzig TE, Lust JA, LACY MQ ET AL. A trial of three regimens for primary amyloidosis: colchicine alone, melphalan and prednisone, and melphalan, prednisone, and colchicine. N Engl J Med 1997; 336: 1202-7.

4. MERLNI G. Treatment of primary amyloidosis. Semin Hematol 1995; 32: 60-79.

5. Skinner M, Sanchorawala V, Seldin DC, Dember LM, FALK RH, BERK JL ET AL. High-dose melphalan and autologous stem-cell transplantation in patients with AL amyloidosis: an 8-year study. Ann Intern Med 2004; 140: 85-93.

6. Fadia A, Casserly LF, Sanchorawaia V, Seidin DC, WrIGHT DG, SKINNER M ET AL. Incidence and outcome of acute renal failure complicating autologous stem mejorando progresivamente su filtración glomerular, hasta ser dada de alta con creatininemia cercana a su basal. El compromiso renal ocumió en concomitancia con una brusca caída en el recuento de glóbulos blancos y con marcadores bioquímicos sugerentes de lisis celular (hiperfosfatemia, hiperuricemia, aumento de láctico-deshidrogenasa). Se descartaron otras causas de IRA: no se utilizaron drogas nefrotóxicas, no existían evidencias de compromiso séptico ni hemodinámico, el flujo sanguíneo renal era normal, no había rabdomiolisis ni anemia hemolítica microangiopática y la uricosuria a $\mathrm{pH}$ urinario alcalino era normal. En consecuencia, es altamente probable que la causa de la IRA haya sido el SLGB.

El uso de melfalán en dosis mieloablativas asociado a trasplante autólogo de células troncales hematopoyéticas, pese a tener elevadas morbilidad $\mathrm{y}$ mortalidad asociadas, mejora significativamente la sobrevida a largo plazo de la amiloidosis AL, y es capaz de inducir remisión de la enfermedad clonal y del compromiso tisular por amiloide ${ }^{10,11}$. Un año y diez meses después de la terapia, nuestra paciente realiza una vida familiar y laboral normal y tiene evidencias de respuesta hematológica completa, filtración glomerular normal y ausencia de proteinuria.

cell transplantation for AL amyloidosis. Kidney Int 2003; 63: 1868-73.

7. GerTZ MA, LACY MQ, DispenZIERI A. Immunoglobulin light chain amyloidosis and the kidney. Kidney Int 2002; 61: 1-9.

8. Atkinson K, Biggs J, Concannon A, Dodds A, Dale B, Norman J. Second marrow transplants for recurrence of haematological malignancy. Bone Marrow Transplant 1986; 1: 159-66.

9. Herget-Rosenthal S, Uppenkamp M, Beelen D, Kohl D, KriBben A. Renal complications of high-dose chemotherapy and peripheral blood stem cell transplantation. Nephron 2000; 84: 136-41.

10. GerTz MA, Lacy MQ, DisPenzieri A, Gastineau DA, Chen MG, Ansell SM et al. Stem cell transplantation for the management of primary systemic amyloidosis. Am J Med 2002; 113: 549-55.

11. Snanoudj R, Mamzer-Bruneel MF, Hermine O, GrunFELD JP, Chauveau D. Recovery of acute renal failure and nephrotic syndrome following autologous stem cell transplantation for primary (AL) amyloidosis. Nephrol Dial Transplant 2003; 18: 2175-7. 